\title{
J. Tarrête et C.-T. Le Roux (dir.), 2008 - Archéologie de la France. Le Néolithique
}

\section{CpenEdition}

\section{Journals}

Édition électronique

URL : http://journals.openedition.org/rao/767

DOI : $10.4000 /$ rao. 767

ISBN : 978-2-7535-1608-3

ISSN : 1775-3732

Éditeur

Presses universitaires de Rennes

\section{Édition imprimée}

Date de publication : 20 décembre 2008

Pagination : 393

ISBN : 978-2-7535-0789-0

ISSN : 0767-709X

Référence électronique

" J. Tarrête et C.-T. Le Roux (dir.), 2008 - Archéologie de la France. Le Néolithique », Revue archéologique de l'Ouest [En ligne], 25 | 2008, mis en ligne le 20 décembre 2008, consulté le 03 décembre 2020. URL: http://journals.openedition.org/rao/767 ; DOI : https://doi.org/10.4000/rao.767 
envisager un lien de causalité entre la fondation du sanctuaire et les prémices urbaines de la ville antique de Sées d'une part, son abandon et les débuts de la christianisation dans l'Orne d'autre part. Retour sur le tracé de l'A88 avec l'article suivant, dû à L. Le Gaillard, qui nous livre les principaux acquis de la fouille d'une villa gallo-romaine à Marcei. Cet établissement d'envergure, comparable à d'autres grandes villae de la région normande, connait une évolution importante au cours du Haut et du Bas-Empire, traduite par trois états successifs. La dernière phase d'occupation manifeste cependant un déclin notable. Arguant de l'exiguïté du décapage (lié à l'emprise autoroutière), l'auteur conclut un peu curieusement sur une discussion autour de ses incertitudes quant à l'identification définitive du site en tant que villa, au détriment de l'hypothèse d'un sanctuaire, et préconise le recours à des investigations plus étendues. La fouille de Marcei laisse place à un nouveau diagnostic, conduit à Sées par le même auteur, à l'occasion duquel ont été mis au jour et analysés divers témoins d'habitat et d'activité métallurgique remontant au $\mathrm{I}^{\mathrm{er}}$ siècle après J.-C. L'histoire du chef-lieu sagien est évoquée à partir d'une cartographie minutieuse des vestiges antiques, médiévaux et modernes recensés à ce jour. Puis les vestiges sont présentés en détail, intégrant études de mobilier (céramique) et de déchets métallurgiques. Les acquis de cette opération sont, pour finir, replacés dans le contexte général de l'histoire du cœur urbain.

La dernière contribution concerne le Moyen Âge, avec une étude d'archéologie du bâti dédiée à la Maison des Sept-Colonnes, imposant édifice à pan de bois construit sur quatre niveaux, sis en plein centre de la ville médiévale d'Alençon, qu'a étudié J.-D. Desforges dans le cadre d'un important projet de restauration. L'histoire détaillée de cet édifice inscrit à l'Inventaire du Patrimoine est relatée depuis ses origines lointaines ( $\mathrm{XI}^{\mathrm{e}}$-XII ${ }^{\mathrm{e}}$ siècles), et agrémentée d'une riche iconographie, avant d'aboutir aux schémas de restitution des façades, aux plans des caves et du rez-de-chaussée.

On ne sait au juste si cet ouvrage contribuera effectivement, ainsi que l'annonce le préfacier, à " forger l'Orne du $\mathrm{XXI}^{\mathrm{e}}$ siècle ». Peu importe en définitive, car les actualités qu'il contient offrent un réel intérêt non seulement pour la fratrie des érudits départementaux, mais aussi pour l'ensemble de la communauté historienne et archéologue régionale. On peut seulement déplorer, outre le choix " un tantinet " austère de la couverture au regard d'une belle iconographie en couleurs insérée dans le volume (un aplat terreux surplombé par quelques gravats et deux sacs-poubelles pour évoquer le majestueux Camp de Bierre!), le caractère éphémère de certaines données (diagnostics), ou encore la brièveté de certaines analyses portant sur des thématiques d'actualité qui requièrent, dans l'avenir, de plus amples développements. En bref, une lecture utile pour prendre la mesure des recherches archéologiques en cours dans ce secteur encore méconnu mais assurément prometteur de la Basse-Normandie.

Vincent Carpentier (INRAP/ CRAHAM-Centre Michel de Boüard, FRE (UCBN-CNRS) n ${ }^{\circ} 3119$ )

Tarrête, J. et Le Roux, C.-T. (dir.), 2008 - Archéologie de la France. Le Néolithique, Paris, Picard (coédition Ministère de la Culture et de la Communication) (88€ jusqu’au 31 janvier 2009, puis $110 €)$.

Il en est parfois des beaux projets comme des beaux bébés : leur accouchement peut être long et laborieux. Lancée voici plusieurs années par la Sous-direction de l'Archéologie, l'idée ambitieuse de publier une "somme» sur le Néolithique français avait impliqué de rassembler les compétences d'une trentaine de spécialistes. Non sans difficultés, la gageure a pu être tenue et le résultat, après une préface de J. Guilaine et quelques documents de présentation générale, s'articule en quelque 27 chapitres, eux-mêmes regroupés en cinq grandes parties :

- l'homme et son environnement : la domestication de la nature (méthodologies, milieux physiques, environnements végétaux, relations homme - animal...);

- l'habitat: de la maison au village, organisation spatiale, architecture, vie domestique et structure sociale;
- les artefacts : matières premières et fabrications (de la pierre - siliceuse ou non - aux balbutiements de la métallurgie en passant par l'os, le cuir, l'argile, le bois, la vannerie, le textile...);

- les vivants et les morts : pratiques et architectures funéraires (le mégalithisme certes, mais pas seulement, loin de là...);

- relations sociales : art et symboles (la circulation des hommes et des biens, l'expression artistique sous toutes ses formes...).

La RAO a plaisir à annoncer l'arrivée de ce beau volume sans nul doute appelé à faire date chez les néolithiciens; elle se promet d'en donner une analyse détaillée dans sa prochaine livraison. 